\title{
Low glucose level and low pH alter the electrochemical function of human parietal pleura
}

\author{
V.K. Kouritas*, , C. Hatzoglou*, C.N. Foroulis" ${ }^{\#}$ A. Hevas", \\ K.I. Gourgoulianis and P.A. Molyvdas*
}

ABSTRACT: The aim of the present study was to investigate whether low glucose and pH level, which are usually measured in complicated pleural effusions, alter the electrochemical function of healthy human parietal pleura.

Parietal pleural pieces were stripped from 66 patients during thoracic surgery and were mounted in Ussing chambers. Krebs' solutions containing different glucose levels $(0,40$ and $100 \mathrm{mg}$ ) and balanced at different $\mathrm{pH}$ levels $(7.4,7.3$ and 7.2$)$ were added to the pleural cavity surface of the pieces. Transmesothelial potential difference was measured at various time-points as an electrophysiological variable and transmesothelial resistance (RTM) was calculated using Ohm's law.

When normal-glucose Krebs at $\mathrm{pH} 7.45$ was used, RTM remained unchanged over time, but when low-glucose Krebs was used, RTM decreased. Krebs without glucose caused the greatest decrease in RTM. Use of low-pH Krebs decreased RTM. The lower the pH of the Krebs, the faster the decrease in RTM and the greater the effect. The decrease in RTM was greater with low$\mathrm{pH}$ than with low-glucose Krebs. Low glucose and low $\mathrm{pH}$ caused an additive decrease in RTM.

Low glucose concentration and low $\mathrm{pH}$ cause alteration of the electrochemical function of human parietal pleura and could act as agents that lead to further exudate progression.

KEYWORDS: Exudates, glucose, human, parietal pleura, $\mathrm{pH}$, transmesothelial resistance

ow glucose level and low $\mathrm{pH}$ often characterise effusions complicating malignancies, mainly primary lung cancer, or autoimmune diseases such as rheumatoid arthritis. They are considered as biochemical indicators of complicated parapneumonic effusions [1-3], which can aid diagnosis [1, 3].

Possible explanations for the decreased glucose level or low $\mathrm{pH}$ of these effusions include: increased utilisation of glucose by abnormal (e.g. bacterial metabolism) or defence cells (e.g. leukocytes) in the pleural cavity; the abnormal transference of substrates across the diseased or inflammatory pleural membrane [1, 3-5]; and the phagocytosis of bacteria along with the release of cell wall components $[3,4,6,7]$.

The purpose of the present study was to investigate whether low glucose level and low $\mathrm{pH}$ can alter the electrochemical function of the healthy human parietal pleura.

\section{MATERIALS AND METHODS}

\section{Study subjects}

Human parietal pleura specimens were obtained from 66 patients who underwent thoracic surgery. The mean age was 62.5 yrs. The mean serum glucose was $108 \mathrm{mg} \cdot \mathrm{dL}^{-1}$. Patients who developed parapneumonic effusions or whose pre-operative serum glucose level was abnormal, were excluded from the study. A piece of each stripped pleural specimen was sent for histopathological examination. All specimens included in the study were shown by the histopathological report to be free of disease. The remainder of each specimen was placed in Krebs' (KRB) solution, pre-oxygenated with $95 \% \mathrm{O}_{2}: 5 \% \mathrm{CO}_{2}$, and transferred to the laboratory within $30 \mathrm{~min}$.

The study was approved by the local ethics committee (University of Thessaly, Larissa, Greece) and informed consent was obtained from all patients participating in the study.

\section{AFFILIATIONS}

*Dept of Physiology, University of Thessaly Medical School, Depts of ${ }^{\#}$ Cardiothoracic Surgery, and

"Thoracic Diseases, Larissa University Hospital, Larissa, Greece.

\section{CORRESPONDENCE}

V.K. Kouritas

Dept of Physiology

University of Thessaly Medical

School

22 Papakiriazi St

41222

Larissa

Greece

Fax: 302410670100

E-mail: kouritas@otenet.gr

Received:

April 052006

Accepted after revision:

April 102007

STATEMENT OF INTEREST

None declared.

Online ISSN 1399-3003 


\section{Study design}

Complicated pleural effusions were simulated with KRB solutions containing different glucose concentrations, balanced at different $\mathrm{pH}$ levels, which were added to the pleural surface of the tissue. Electrophysiological parameters were measured.

\section{Methods}

The specimens were examined for holes, fat tissue or residual blood clots. The initial KRB was balanced at $\mathrm{pH} 7.45$, cooled to $4{ }^{\circ} \mathrm{C}$, and contained (in $\mathrm{mM}$ ) $117.5 \mathrm{NaCl}, 1.15 \mathrm{NaH}_{2} \mathrm{PO}_{4}, 24.99$ $\mathrm{NaHCO}_{3}, 5.65 \mathrm{KCl}, 1.18 \mathrm{MgSO}_{4}, 2.52 \mathrm{CaCl}_{2}$ and 5.55 glucose.

The specimens were mounted as planar sheets between Ussing-type chambers. The tissue was bathed with KRB on both sides and bubbled with a $95 \% \mathrm{O}_{2}: 5 \% \mathrm{CO}_{2}$ gas mixture heated to $37^{\circ} \mathrm{C}$.

The transmesothelial potential difference (PDTM) was measured with $3 \mathrm{M} \mathrm{KCl} \mathrm{3 \%} \mathrm{agar} \mathrm{bridges} \mathrm{connected} \mathrm{to} \mathrm{silver/silver}$ chloride electrodes, and the output was amplified (model DVC-3; World Precision Instruments, Sarasota, FL, USA). Current was provided by a voltage-clamp apparatus (model DVC-1000; World Precision Instruments).

The specimens were equilibrated for $30 \mathrm{~min}$. Control PDTM was measured in the absence of current and after the application of currents ranging $-400-400 \mu \mathrm{A}$ [8]. A total of 66 control experiments were carried out.

KRB solutions containing 100, 40 and $0 \mathrm{mg}$ glucose $(n=10$ experiments for each glucose concentration) were added to the pleural surface. KRB solutions balanced at $\mathrm{pH} 7.4,7.3$ and 7.2 $(\mathrm{n}=9$ experiments for each $\mathrm{pH})$ were also used. Experiments were also conducted with KRB solutions without glucose, balanced at $\mathrm{pH} 7.2$ ( $\mathrm{n}=9$ experiments). The chamber facing the outer-pleural surface was filled with $5.55 \mathrm{mM}$ glucose KRB balanced at $\mathrm{pH} 7.45$, ensuring tissue viability $[9,10]$. PDTM was measured 1, 5, 10, 30, 45 and $60 \mathrm{~min}$ after the addition of each solution.

Transmesothelial resistance (RTM) was calculated from PDTM using Ohm's law [8]. Change in RTM was calculated by subtracting the mean RTM from the mean control values at the same time-point.

\section{Analysis}

Data are expressed as mean \pm SEM or as the change of RTM. Statistical significance was determined by paired t-test. The statistical significance of RTM changes between groups was determined by ANOVA. A p-value $<0.05$ was accepted as significant.

\section{RESULTS}

RTM remained constant throughout the experiments using normal-glucose KRB at $\mathrm{pH} 7.45$.

\section{Low-glucose KRB}

$R T$ M decreased $10 \mathrm{~min}$ after the addition of $40 \mathrm{mg}$ glucose KRB (fig. 1a) and decreased significantly after $45(\mathrm{p}=0.020)$ and $60 \mathrm{~min}\left(18.65 \pm 0.3 \Omega \cdot \mathrm{cm}^{-2} ; \quad \mathrm{p}=0.009\right)$. RTM was similarly decreased $5 \mathrm{~min}$ after the addition of $0 \mathrm{mg}$ glucose KRB (fig. 1a), and was significantly decreased from $10 \mathrm{~min}$ $(p=0.034)$ until $60 \mathrm{~min}\left(18.20 \pm 0.3 \Omega \cdot \mathrm{cm}^{-2} ; \mathrm{p}=0.001\right)$. The net
RTM change was more intense $(p=0.024) 30$ min after the addition of glucose KRB than $30 \mathrm{~min}$ after the addition of $40 \mathrm{mg}$ glucose KRB (fig. 1b). This was also true after 45 $(\mathrm{p}=0.011)$ and $60 \mathrm{~min}\left(0.67 \pm 0.2 \Omega \cdot \mathrm{cm}^{-2}\right.$ for $40 \mathrm{mg}$ glucose KRB versus $1.12 \pm 0.2 \Omega \cdot \mathrm{cm}^{-2}$ for $0 \mathrm{mg}$ glucose $\mathrm{KRB}$; $\mathrm{p}=0.009$ ).

\section{Low-pH KRB}

RTM had decreased $60 \min \left(18.44 \pm 0.2 \Omega \cdot \mathrm{cm}^{-2} ; \mathrm{p}=0.049\right)$ after the addition of pH 7.4 KRB (fig. 2a). RTM had decreased 10 min after the addition of $\mathrm{pH} 7.3 \mathrm{KRB}$ (fig. 2a), and had decreased significantly after $45(p=0.035)$ and $60 \mathrm{~min}$ $\left(17.42 \pm 0.2 \Omega \cdot \mathrm{cm}^{-2} ; \mathrm{p}=0.003\right)$. When $\mathrm{pH} 7.2 \mathrm{KRB}$ was used, RTM decreased from the 1st min (fig. 2a), and RTM was significantly decreased from $10 \mathrm{~min}(\mathrm{p}=0.048)$ until $60 \mathrm{~min}$ $\left(15.54 \pm 0.4 \Omega \cdot \mathrm{cm}^{-2} ; \mathrm{p}=0.002\right)$. The change in $R \mathrm{TM}$ was more
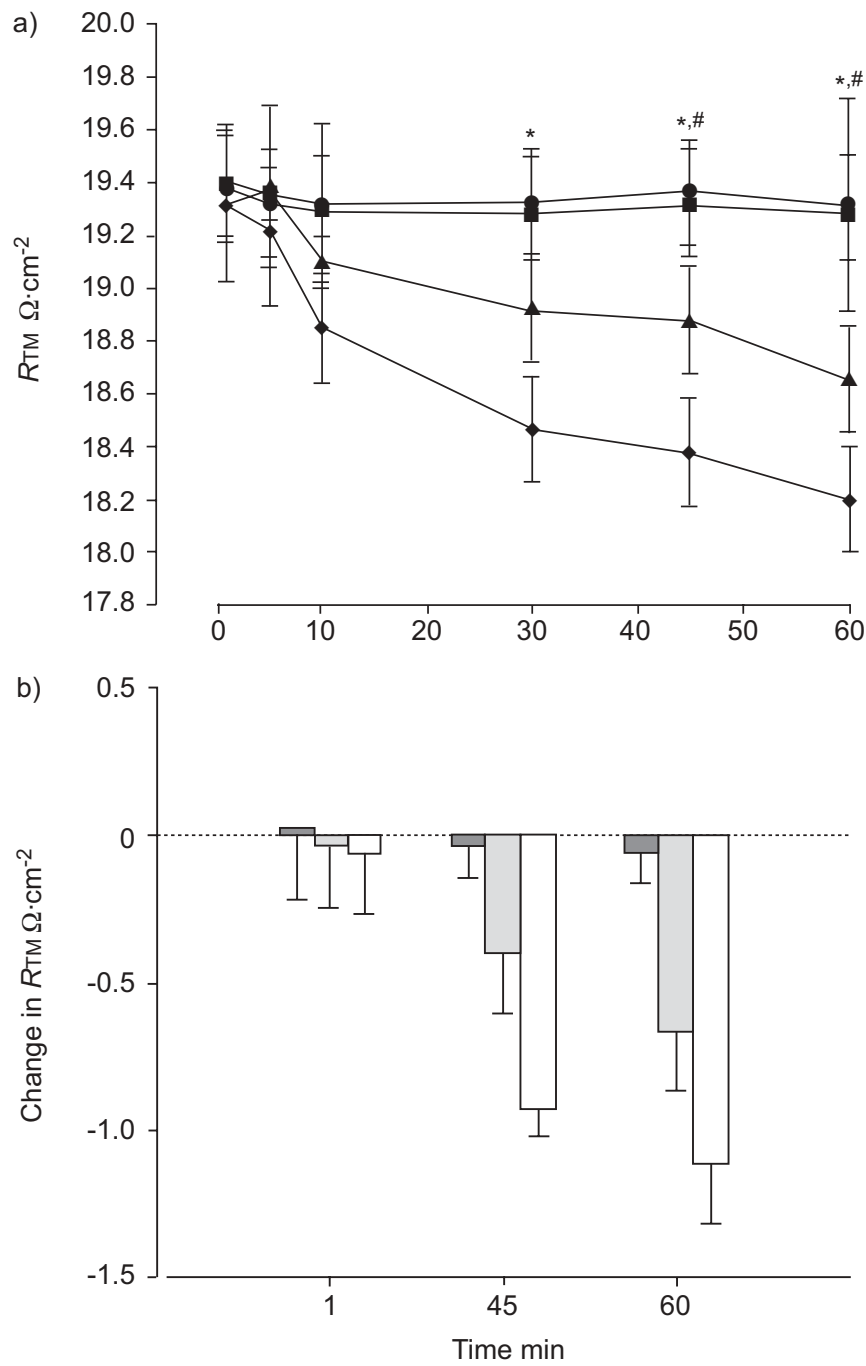

FIGURE 1. a) Transmesothelial resistance (RTM) after addition of Krebs solution with different glucose concentrations to the pleural surface. Data are presented as mean \pm SEM, $n=10$ for each glucose concentration. - control; - : Krebs' + $100 \mathrm{mg}$ glucose; $\mathbf{\Lambda}:$ Krebs' $+40 \mathrm{mg}$ glucose; $\$$ : Krebs' without glucose. *: $p<0.05$ versus control; ${ }^{*}: p<0.05$ between groups. b) Change in RTM after the 1st, 45th and 60th mins. $\square:$ Krebs' $+100 \mathrm{mg}$ glucose; 1 : Krebs' $+40 \mathrm{mg}$ glucose; $\square$ : Krebs' without glucose. 

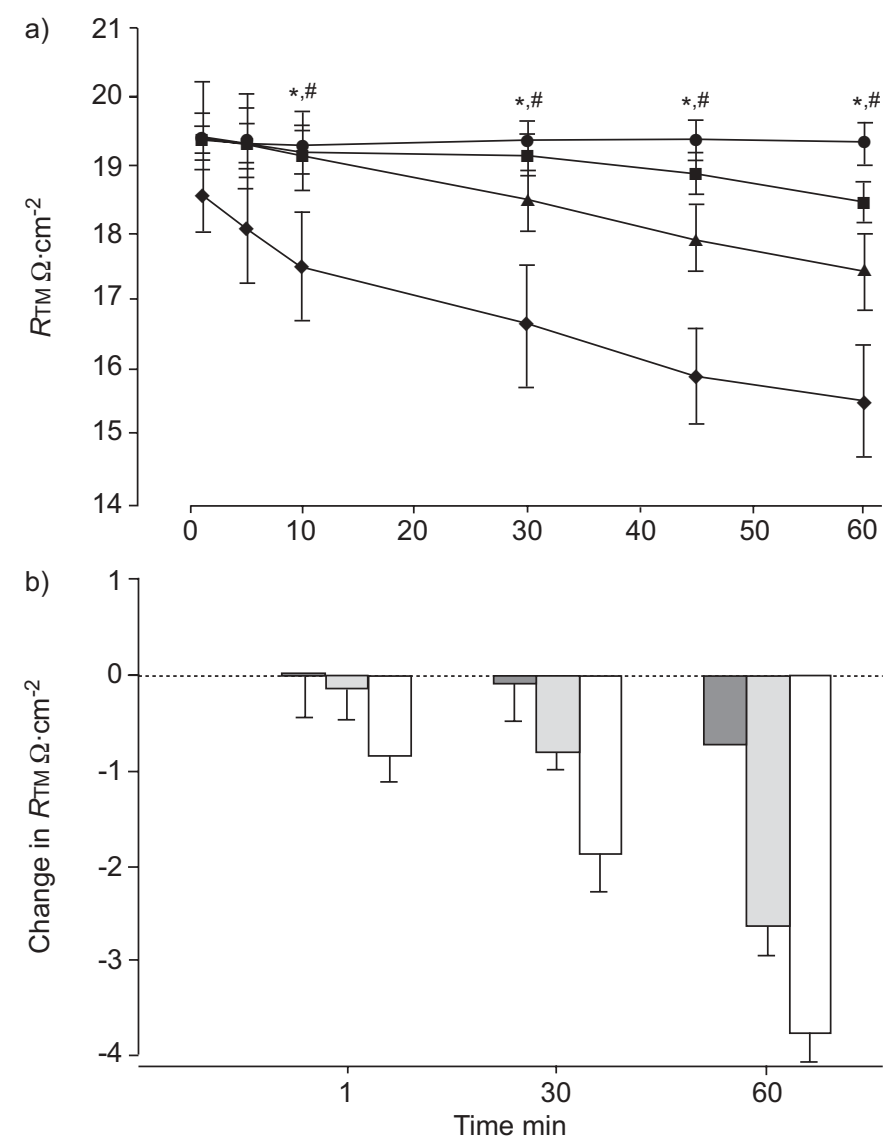

FIGURE 2. a) Transmesothelial resistance (RTM) after addition of Krebs' solution with different $\mathrm{pH}$ values to the pleural surface. Data are presented as mean \pm SEM, $\mathrm{n}=9$ for each $\mathrm{pH}$. $\bullet$ : control; $\mathbf{\square}$ : Krebs at $\mathrm{pH} 7.4$; $\mathbf{\Delta}$ : Krebs at $\mathrm{pH} 7.3$ glucose; Krebs at pH 7.2. *: $p<0.05$ versus control; ${ }^{*}: \mathrm{p}<0.05$ between groups. b) Change in RTM after the 1st, 30th and 60th mins. $\square$ : Krebs at pH 7.4; 1 : Krebs at $\mathrm{pH} 7.3$; 1 : Krebs at $\mathrm{pH} 7.2$.

intense for $\mathrm{pH} 7.2 \mathrm{KRB}$ than for $\mathrm{pH} 7.4(\mathrm{p}=0.010)$ and $\mathrm{pH} 7.3$ KRB $(p=0.008)$ after $30 \mathrm{~min}\left(3.76 \pm 0.2 \Omega \cdot \mathrm{cm}^{-2}\right.$ versus $0.74 \pm$ $\left.0.3 \Omega \cdot \mathrm{cm}^{-2} ; \mathrm{p}=0.005\right)$ and after $60 \mathrm{~min}\left(3.76 \pm 0.2 \Omega \cdot \mathrm{cm}^{-2}\right.$ versus $2.64 \pm 0.2 \Omega \cdot \mathrm{cm}^{-2} ; \mathrm{p}=0.037$; fig. $\left.2 b\right)$.

\section{Low-glucose and low-pH KRB}

$R$ TM had decreased immediately and significantly 5 min after the addition of $\mathrm{pH} 7.2 \mathrm{KRB}$ without glucose (17.94 \pm $0.4 \Omega \cdot \mathrm{cm}^{-2} ; \mathrm{p}=0.049$; fig. 3a), after $30 \mathrm{~min}(\mathrm{p}=0.005)$ and after $60 \min \left(14.23 \pm 0.4 \Omega \cdot \mathrm{cm}^{-2} ; \mathrm{p}=0.001\right)$. The net $R \mathrm{TM}$ decrease caused by $\mathrm{pH} 7.2 \mathrm{KRB}$ was greater $(\mathrm{p}=0.001)$ than that caused by KRB without glucose (fig. 3b) $10 \mathrm{~min}$ after addition. The $R T M$ decrease caused by no-glucose $\mathrm{pH} 7.2 \mathrm{KRB}$ was even greater ( $\mathrm{p}=0.002$ versus RTM drop with no-glucose KRB; $\mathrm{p}=0.937$ versus $\mathrm{RTM}$ drop with $\mathrm{pH} 7.2 \mathrm{KRB}$ ) and this drop became significant from the 5 th min after addition.

\section{DISCUSSION}

The main finding of the current study is that solutions with low glucose and/or low $\mathrm{pH}$ caused electrochemical alterations of the healthy human parietal pleura. PDTM and RTM were decreased, suggesting that the electrochemical transport ability of the pleura had increased [9]. The RTM decrease was quicker
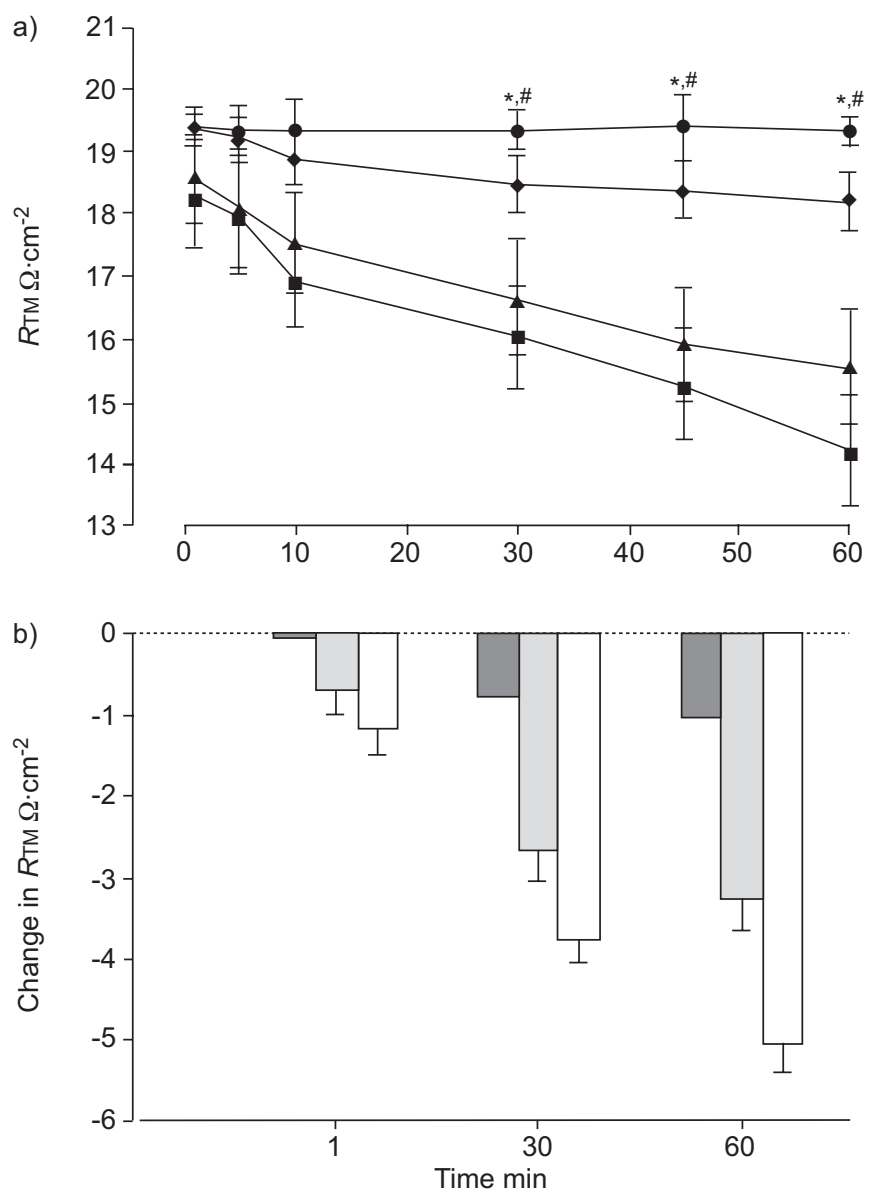

FIGURE 3. a) Transmesothelial resistance (RTM) after addition of Krebs solution with different glucose concentrations and/or $\mathrm{pH}$ levels to the pleural surface. Data are presented as mean $\pm \mathrm{SEM}, \mathrm{n}=9$ for each glucose concentration. - : control; $\boldsymbol{\nabla}$ : Krebs' without glucose; $\mathbf{\Delta}$ : Krebs' at pH 7.2; $\mathbf{\square}$ : Krebs' without glucose at $\mathrm{pH}$ 7.2. * : $\mathrm{p}<0.05$ versus control; ${ }^{*}: \mathrm{p}<0.05$ between groups. b) Change in RTM after the 1st, 30th and 60th mins. $\square$ : Krebs' without glucose; 1 : Krebs' at $\mathrm{pH} 7.2$; 1 : Krebs' without glucose at $\mathrm{pH} 7.2$.

and more intense as less glucose and lower-pH KRB were used. Lower $\mathrm{pH}$ was observed to be more potent than low glucose in altering the electrochemistry of the pleural membrane. Finally, the effects caused by low glucose and low $\mathrm{pH}$ seem to be additive.

The pleural membrane is considered to be "leaky", allowing solutes and substrates to be transported [8, 10]. Glucose entry to epithelial cells, apart from the glucose transporter system, is coupled with sodium via the sodium-glucose co-transporter [9]. This could provide an osmotic gradient, affecting overall tissue permeability $[11,12]$, which in the current study is also suggested by the observed decrease of PDTM and RTM [9]. It has been suggested that active electrolyte transportation across the pleural mesothelium involves $\mathrm{Na}^{+} / \mathrm{H}^{+}$exchangers $[8,9]$ and thus $\mathrm{pH}$ could link the acidic environment with electrolyte balance within the pleural cavity.

Low glucose level and low $\mathrm{pH}$ are considered to be biochemical indicators of poor outcome or diagnostic indicators for undiagnosed pleural exudates $[3,6,7,13]$. The results 
of the present study suggest that a normal glucose content and $\mathrm{pH}$ could be important for pleural electrophysiological stability and thus low glucose concentrations or lowered $\mathrm{pH}$ in effusions are not only the result of but are also potent factors in further alteration of pleural function.

Lymphatic drainage impairment is believed to play a key role in exudate formation [14, 15]. Pleural capillary permeability alterations involve an increase in water and electrolyte transportation and macromolecule leakage [16]. Disease cells $[1,3]$, bacteria, inflammatory cells and mediators $[1,4]$ interact with the mesothelium causing altered selectivity, increased permeability [17] and decreased fluid removal [18], leading to further fluid accumulation and substrate imbalance. This substrate (glucose) imbalance can itself further change the pleural function. A more acidic pleural environment impairs the pleural function further, leading to a deteriorating cycle of further fluid accumulation, substrate imbalance and a shift to more acidic environment. In the present study, this process was greater and faster when greater substrate imbalance or a more acidic environment was simulated.

In conclusion, reduced glucose content and/or low $\mathrm{pH}$ of the pleural fluid could alter the progress of effusion by altering the function of the pleural membrane.

\section{REFERENCES}

1 Schiza SE, Antoniou KM, Economidou FN, Siafakas NM. Pharmacotherapy in complicated parapneumonic pleural effusions and thoracic empyema. Pulm Pharmacol Ther 2005; 18: 381-389.

2 Sahn SA. Malignant pleural effusions. In: Shields TW, ed. General Thoracic Surgery. 4th Edn. Philadelphia, Williams and Wilkins, 1994; pp. 757-764.

3 Good JT Jr, Taryle DA, Sahn SA. The pathogenesis of low glucose, low $\mathrm{pH}$ malignant effusions. Am Rev Respir Dis 1985; 131: 737-741.

4 Alfageme I, Munoz F, Pena N, Umbria S. Empyema of the thorax in adults. Etiology, microbiologic findings and management. Chest 1993; 103: 839-843.
5 Rahman NM, Chapman SJ, Davies RJO. Pleural effusion: a structured approach to care. Br Med Bull 2004; 72: 31-47.

6 Potts DE, Taryle DA, Sahn SA. The glucose- $\mathrm{pH}$ relationship in parapneumonic effusions. Arch Intern Med 1978; 138: 1378-1380.

7 Heffner JE, Brown LK, Barbieri C, DeLeo JM. Pleural fluid chemical analysis in parapneumonic effusions. A metaanalysis. Am J Respir Crit Care Med 1995; 151: 1700-1708.

8 Hatzoglou CH, Gourgoulianis KI, Molyvdas PA. Effect of nitroprussid sodium, ouabain and amiloride on the electrical potential profile of isolated sheep pleura. J Appl Physiol 2001; 90: 1565-1569.

9 Hatzoglou CH, Gourgoulianis KI, Hatzoglou A, Castanas E, Molyvdas PA. Rapid effects of $17 \beta$-estradiol and progesterone on sheep visceral and parietal pleurae via a nitric oxide pathway. J Appl Physiol 2002; 93: 752-758.

10 Cox M, Singer I. Insulin mediated $\mathrm{Na}+$ transport in the toad urinary bladder. Am J Physiol 1977; 232: 270-277.

11 Zeuthen T. General models for water transport across leaky epithelia. Int Rev Cytol 2002; 215: 285-317.

12 Kolka CM, Rattigan S, Richards SM, Barrett EJ, Clark MG. Endothelial Na+-D-glucose cotransporter: no role in insulin-mediated glucose uptake. Horm Metab Res 2005; 37: 657-661.

13 Light RW, Girard WM, Jenkinson SG, George RB. Parapneumonic effusions. Am J Med 1980; 69: 507-512.

14 Judson MA, Sahn SA. The pleural space and organ transplantation. Am J Respir Crit Care Med 1996; 153: 1153-1165.

15 Light RW, Broaddus VC. Pleural effusion. In: Murray JF, Nadel JA, Mason RJ, Boushey HA Jr, eds. Textbook of Respiratory Medicine. Philadelphia, WB Saunders, 2000; pp. 2013-2042.

16 Michel CC, Curry FE. Microvascular permeability. Physiol Rev 1999; 79: 703-761.

17 Lieberman FL, Hidemura R, Peters RL, Reynolds TB. Pathogenesis and treatment of hydrothorax complicating cirrhosis with ascites. Ann Intern Med 1966; 64: 341-351.

18 Zocchi L. Physiology and pathophysiology of pleural fluid turnover. Eur Respir J 2002; 7: 28-49. 